\title{
Snow specific surface area simulation using the one-layer snow model in the Canadian LAnd Surface Scheme (CLASS)
}

\author{
A. $\operatorname{Roy}^{1}$, A. Royer ${ }^{1}$, B. Montpetit ${ }^{1}$, P. A. Bartlett ${ }^{2}$, and A. Langlois ${ }^{1}$ \\ ${ }^{1}$ Centre d'Applications et de Recherches en Télédétection (CARTEL), Université de Sherbrooke, 2500 Boulder Université, \\ J1K2R1 Sherbrooke, QC, Canada \\ ${ }^{2}$ Climate Processes Section, Environment Canada, 4905 Dufferin street, M3H 5T4 Toronto, ON, Canada
}

Correspondence to: A. Roy (alexandre.r.roy@usherbrooke.ca)

Received: 27 November 2012 - Published in The Cryosphere Discuss.: 18 December 2012

Revised: 29 April 2013 - Accepted: 24 May 2013 - Published: 20 June 2013

\begin{abstract}
Snow grain size is a key parameter for modeling microwave snow emission properties and the surface energy balance because of its influence on the snow albedo, thermal conductivity and diffusivity. A model of the specific surface area (SSA) of snow was implemented in the one-layer snow model in the Canadian LAnd Surface Scheme (CLASS) version 3.4. This offline multilayer model (CLASS-SSA) simulates the decrease of SSA based on snow age, snow temperature and the temperature gradient under dry snow conditions, while it considers the liquid water content of the snowpack for wet snow metamorphism. We compare the model with ground-based measurements from several sites (alpine, arctic and subarctic) with different types of snow. The model provides simulated SSA in good agreement with measurements with an overall point-to-point comparison RMSE of $8.0 \mathrm{~m}^{2} \mathrm{~kg}^{-1}$, and a root mean square error (RMSE) of $5.1 \mathrm{~m}^{2} \mathrm{~kg}^{-1}$ for the snowpack average SSA. The model, however, is limited under wet conditions due to the single-layer nature of the CLASS model, leading to a single liquid water content value for the whole snowpack. The SSA simulations are of great interest for satellite passive microwave brightness temperature assimilations, snow mass balance retrievals and surface energy balance calculations with associated climate feedbacks.
\end{abstract}

\section{Introduction}

Snow grain size is of particular interest for microwave snow emission models, the surface energy balance (albedo and turbulent fluxes) and atmospheric-snow chemistry interactions
(Domine et al., 2008). At high microwave frequencies (generally measured at $19 \mathrm{GHz}$ and $37 \mathrm{GHz}$ ), snow grain size is an important variable affecting snowpack extinction and scattering properties (Kontu and Pulliainen, 2010; Grody, 2008; Durand et al., 2008; Roy et al., 2004). Thus, snow grain size must be considered in microwave snow emission models (MSEM) for the retrieval of snow properties from satellite passive microwave observations (Langlois et al., 2012; Huang et al., 2012; Pardé et al., 2007). Hence, in passive microwave applications, prior information such as snow grain size from a snowpack physical model is required for snow water equivalent (SWE) estimates (Durand and Liu, 2012). The surface albedo is also sensitive to the snow grain size and its vertical profile (Wiscombe and Warren 1980; Jin et al., 2008; Lyapustin et al., 2009; Aoki et al., 2011). Gardner and Sharp (2010) found that the broadband albedos of snowpacks show a logarithmic relationship with specific surface area (SSA). The thermal properties of snow, such as snow conductivity and diffusivity, are also related to snow microstructure (Domine et al., 2008; Adams and Sato, 1993). Surface albedo and snow conductivity are thus key parameters for modeling the surface energy balance in order to understand the impact of snow cover on global and regional climate dynamics (Armstrong and Brun, 2008). They also have a major impact on the prediction of the snow water equivalent as well as the timing of melt onset (Franz et al., 2010).

However, many snow evolution models do not take into account snow grain size. The Canadian LAnd Surface Scheme (CLASS: Verseghy, 1991; Verseghy et al., 1993) is used in the Canadian global circulation models (Scinocca et al., 2008) and the Canadian Regional Climate Model (CRCM: 
Music and Caya, 2007; Caya and Laprise, 1999); it includes a one-layer snow model that does not simulate snow grain metamorphism. This is a major limitation for the assimilation of passive microwave brightness temperature $\left(T_{\mathrm{B}}\right)$ data for the improvement of snow simulations. In the context of data assimilation, where physical and emission models of snow are coupled, estimates of snow grain size are needed (Durand et al., 2009; Toure et al., 2011; Langlois et al., 2012). The implementation of snow grain metamorphism within CLASS is thus of particular interest for assimilation purposes. This implementation is not, however, straightforward in a one-layer snow model because snow metamorphism depends on many variables, such as snow age and the temperature gradient, which lead to a stratification of snow layers with different grain sizes. Thus, a major difficulty is that the vertical stratification is not considered in single-layer physical snow models. This study aims to address this issue, as simply as possible, using the CLASS one-layer snow evolution model. Even if one layer snow models are less physically correct then multi-layered models (Brun et al., 1992; Bartlelt et al., 2002; Bougamont et al., 2005; Ettema et al., 2010; Niwano et al., 2012), the SnowMIP experiments have shown that CLASS performs relatively well (Brown et al., 2006; Rutter et al., 2009). Furthermore, in climate and meteorological models, the errors in snow simulations are often related to the precipitation inputs. Hence, in these contexts, a more complex multi-layer model would not necessarily produce better results.

Grain size is a parameter that is difficult to characterize accurately and measure in the field. The specific surface area (SSA), which represents the ratio of the surface area per unit of mass, is a well-defined parameter representing the geometric characteristics of a porous medium, such as snow (Dominé et al., 2001). Methods based on snow reflectance in the shortwave infrared (SWIR) can now provide rapid and reproducible field measurements of SSA (Gallet et al., 2009; Arnaud et al., 2011; Montpetit et al., 2012), which can be related theoretically to grain size. SSA can be related to the radius of a monodisperse collection of ice spheres, each having the same surface area to volume ratio, called the optical radius $\left(R_{\text {opt }}\right)$ :

$$
R_{\mathrm{opt}}=\frac{3}{\rho_{\text {ice }} \mathrm{SSA}}
$$

Recent studies have shown that SSA offers a reliable representation of snow grain size in the context of microwave emission snow modeling (MESM) (Roy et al., 2013; Montpetit et al., 2013; Brucker et al., 2011). These studies showed that a scaling factor on $R_{\mathrm{opt}}$ derived from SSA is required to simulate brightness temperatures in order oversimplification of snow grain representation in models. From a good representation of snow grain size in the snowpack for microwave emission simulations, it is possible to determinate which part of the signal is attributable to snow grain and which is attributable to other snow characteristics of interest like SWE.
Considering the importance of snow grain size and the advances made in snow microstructure characterization with the SSA metric, many studies have developed approaches for modeling the evolution of SSA throughout the winter season. Cabanes et al. (2003) first proposed an empirical exponential decay function of time and temperature for snow SSA. Legagneux et al. (2003) showed, using laboratory experiments under isothermal conditions, that the decreasing trend of SSA is best fitted using a logarithmic function. That trend has also been confirmed with X-ray microtomography measurements (Flin et al., 2004; Kaempfer and Schneebeli, 2007; Chen and Baker, 2010). Taillandier et al. (2007), using methane adsorption SSA measurements (Domine et al., 2001) in a taiga environment, proposed empirical relationships for the decrease of SSA as a function of time based on the snow age, snow temperature and the temperature gradient within the snowpack. A similar approach relating SSA to snow type (fresh snow, recognizable particles, aged and rounded crystals, aged and faceted crystals, and depth hoar) and snow density was developed by Domine et al. (2007). Jacobi et al. (2010) implemented these last two approaches in the Crocus multi-layer snow model (Brun et al., 1992). With the model based on snow type and density (Domine et al., 2007), SSA was overestimated in surface snow, but this was mainly because Crocus underestimated density, as this model does not take into account the upward water vapor flux induced by the large temperature gradient in the subarctic snowpack (Taillandier et al., 2006); however, a generally good agreement between SSA simulations and measurements (methane adsorption) was observed when the SSA was calculated based on prognostic equations using snow age (Taillandier et al., 2007). Flanner and Zender (2006) developed a physically-based model to predict the evolution of dry snow SSA. The model considers the snow temperature, temperature gradient and snow density and uses two adjustable parameters for the distribution of crystal sizes and for the irregularity in particle spacing. A weakness of most of these previous approaches is that the wet snow metamorphism is not taken into account, whereas water within the snowpack leads to a drastic decrease of SSA (wet snow metamorphism) due to rapid rounding and an increase in the size of snow grains (Brun, 1989). However, Flanner et al. (2007) implemented wet snow metamorphism following Brun (1989) in the model of Flanner and Zender (2006). Note that wind can also have complex effect on snow grains by enhancing the rate of SSA decrease (Cabanes et al., 2003) or, on the contrary, leading to an increase in SSA (Domine et al., 2009). Morin et al. (2013) compared SSA deduced from the $R_{\text {opt }}$ values simulated by Crocus with SSA measured from SWIR reflectance (Gallet et al., 2009) in an alpine environment. They showed qualitative agreement between measured and simulated SSA and that its simulation is difficult under wet snow conditions mostly because of the difficulty in simulating adequately the vertical profile of liquid water content in the snowpack. 
The main objective of this study is to evaluate an offline SSA model implemented in the one-layer CLASS snow model for different northern climate environments. More specifically, the SSA model is a multi-layer snow model driven by CLASS outputs to simulate the evolution of SSA in the different snow layers. The evolution of SSA is computed for dry snow using the model of Taillandier et al. (2007) based on snow aging, and the equation of Brun (1989) for wet snow metamorphism. The simulated SSA values are compared with measured SSA derived from SWIR reflectance (Montpetit et al., 2012; Gallet et al., 2009) for five different sites (two northern mid-latitude, arctic tundra, taiga and alpine) throughout the winter season. The model is developed in a perspective of passive microwave applications for SWE retrievals at a large scale, but could be used for other applications such as snow albedo estimates. The study also provides an additional validation of the Taillandier et al. (2007) equations using new sets of accurate in situ SSA measurements for different environments.

\section{Method}

\subsection{CLASS-SSA model}

The CLASS-SSA model operates in an "offline" mode, meaning that it uses the CLASS simulated state variables to simulate the SSA evolution, but without feedback on the snowpack evolution. The CLASS snow model is a one-layer model (a detailed description of the snow model in CLASS is given in Bartlett et al., 2006; Brown et al., 2006). Version 3.4 of the standalone driver for CLASS (Verseghy, 2009), which allows running the model using meteorological data, was used in this study. CLASS has been designed to run at a time step of $30 \mathrm{~min}$ or less, to ensure numerical stability of the modeled prognostic variables (Verseghy, 2009). In this study, CLASS is run at a time step of $30 \mathrm{~min}$. In our case, the meteorological data used to drive the CLASS model (precipitation rate, air temperature, wind speed, air humidity, and incoming shortwave and longwave radiation) were derived from in situ measurements or from the North American Regional Reanalysis (NARR) data (Mesinger et al., 2006) (more details on driving data are provided in Sect. 2.2). The use of NARR data is motivated by the necessity to run the model at a large scale in the perspective of passive microwave space-borne applications. The thermal conductivity of snow was calculated from snow density using the empirical relationship described in Sturm et al. (1997).

The offline SSA model is a multilayer model, where layer evolution is constrained by snow density, snow depth and SWE from CLASS simulations. Figure 1 shows the flowchart of CLASS-SSA. The SSA evolution of dry snow is based on the logarithmic relationship for snow aging developed by Taillandier et al. (2007). The CLASS-SSA model adds snow layers when snowfall occurs. Consecutive precipitation

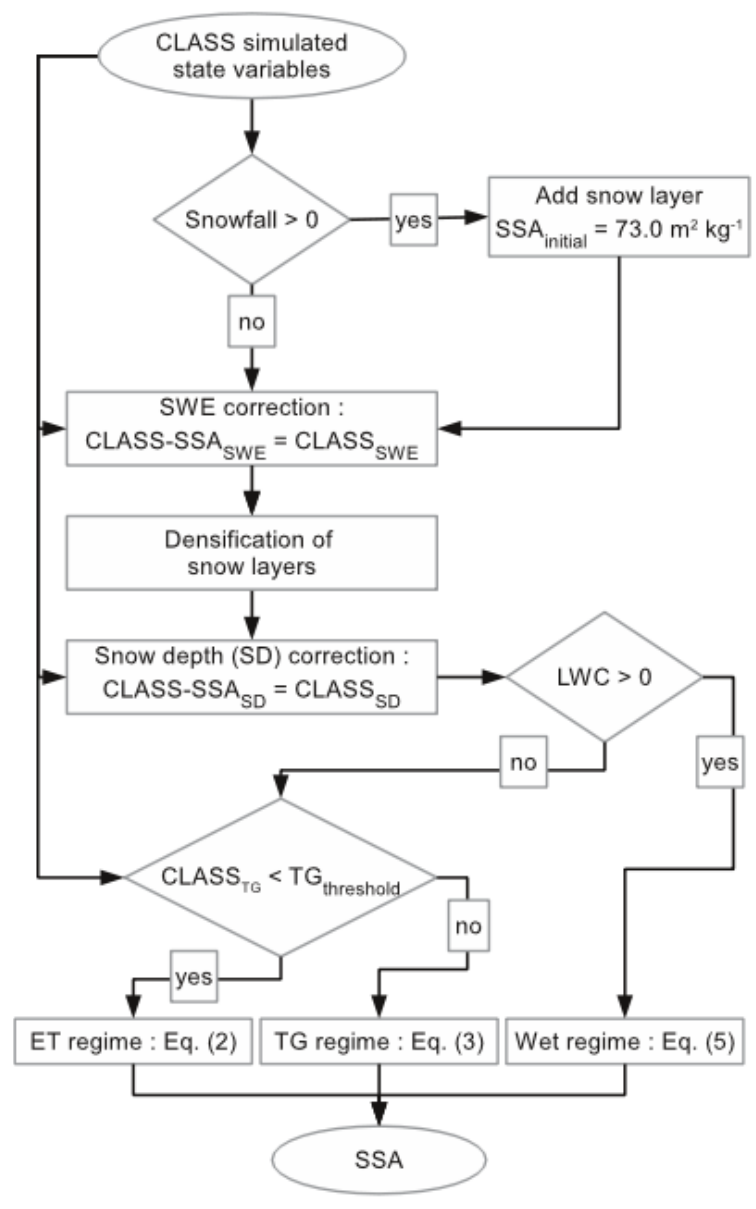

Fig. 1. CLASS-SSA model flow chart.

(precipitation occurring during two or more consecutive time steps) is however considered as one precipitation event and contributes to the same layer. The initial SSA ( $\left.\mathrm{SSA}_{\text {initial }}\right)$ was set to $73.0 \mathrm{~m}^{2} \mathrm{~kg}^{-1}$ (the mean SSA value for fresh snow measured by Domine et al., 2007; the $\mathrm{SSA}_{\text {initial }}$ value is discussed in Sect. 4), and the density of each new snow layer was set to the fresh snow density calculated by CLASS (Hedstrom and Pomeroy, 1998). However, because we want the CLASSSSA model to be coherent with the CLASS snow model, the snow parameters (SWE, snow depth and snow density) of the CLASS-SSA model are corrected during the snowpack evolution in order to match the corresponding values simulated by CLASS. Thus, prior to each time step, a correction factor is applied to the SWE value of every snow layer to fit the multilayer model SWE with the CLASS simulation. A densification routine is then implemented, mostly to estimate the position and thickness of each layer within the snowpack. The same densification model as the one used in CLASS (Bartlett et al., 2006) is applied to every layer. After compaction is applied to each layer, if the summed multilayer snow depth is lower than the snow depth simulated by CLASS, a correction factor is applied to the thickness of the 
top snow layer so that the summed multilayer snow depth corresponds to the snow depth simulated by CLASS (Fig. 1). However, in this context, the top layer cannot be less than $100 \mathrm{~kg} \mathrm{~m}^{-3}$. If it reaches $100 \mathrm{~kg} \mathrm{~m}^{-3}$, densification is applied to the second layer and so on. In this case, the correction is applied only to the top layers to avoid an unrealistic thickening of the dense bottom layers. On the other hand, if the sum of the snow depths for all the layers is higher than the snow depth simulated by CLASS, a correction is applied to all the layers, but the density of any layer cannot exceed the maximum snow density estimated by CLASS. Thus, when the snowpack melts, the density of every layer increases due to the decreasing thickness, leading to wet densification.

The SSA evolution for each snow layer is then calculated considering the model of Taillandier et al. (2007) (Fig. 1). The model parameterizations for SSA evolution are based on snow age and snow temperature $\left(T_{\text {snow }}\right)$. Two algorithms are available, depending on the temperature gradient regime: one for equi-temperature (ET) metamorphism,

$$
\begin{aligned}
& \operatorname{SSA}(t)=\left[0.629 \cdot \mathrm{SSA}_{\text {initial }}-15.0 \cdot\left(T_{\text {snow }}-11.2\right)\right] \\
& -\left[0.076 \cdot \mathrm{SSA}_{\text {initial }}-1.76 \cdot\left(T_{\text {snow }}-2.96\right)\right] \\
& \cdot \ln \left\{t+e^{\frac{-0.371 \cdot \mathrm{SSA}_{\text {initial }}-15.0 \cdot\left(T_{\text {snow }}-11.2\right)}{0.076 \cdot \mathrm{SA}_{\text {initial }}-1.76 \cdot(\text { Snnow }-2.96)}}\right\} ;
\end{aligned}
$$

and the other for strong temperature gradient (TG) metamorphism,

$$
\begin{aligned}
\operatorname{SSA}(t) & =\left[0.659 \cdot \mathrm{SSA}_{\text {initial }}-27.2 \cdot\left(T_{\text {snow }}-2.03\right)\right] \\
& -\left[0.0961 \cdot \mathrm{SSA}_{\text {initial }}-3.44 \cdot\left(T_{\text {snow }}+1.90\right)\right] \\
& \cdot \ln \left\{t+e^{\frac{-0.341 . S \mathrm{SA}_{\text {intial }}-27.2 \cdot\left(T_{\text {snow }}-0.03\right)}{0.0961 \cdot \mathrm{SSA}_{\text {initial }}-3.44 \cdot\left(T_{\text {snow }}+1.900\right)}}\right\}^{\prime}
\end{aligned}
$$

where $t$ is the age of the snow layer in hours. Note that in Eqs. (2) and (3), SSA is in $\mathrm{cm}^{2} \mathrm{~g}^{-1}$. $T_{\text {snow }}$ is the snow layer temperature $\left({ }^{\circ} \mathrm{C}\right)$ calculated by linearly interpolating the air temperature and the CLASS simulated snow-soil interface temperature. Air temperature appears more accurate and representative than the surface (skin) temperature for estimating the snowpack temperature gradient. Figure 2 shows a rapid decrease in the SSA over the first few days, which is related to destructive metamorphism when snow crystals lose most of their complicated shape and break up into smaller grains with less total surface area (Sommerfeld and Lachapelle, 1970). This metamorphic process is faster in warmer snow (higher $T_{\text {snow }}$ ) (Colbeck, 1983). After a few days, the decrease in SSA slows down earlier in the ET regime when compared with the TG regime. The process of constructive metamorphism is dominant when the temperature gradient induces water vapor transport from warm to cold temperatures, causing rapid grain growth from vapor deposition at the bottom of the snow grains (Colbeck, 1983). Hence, in the absence of that mechanism in ET conditions, the decrease in SSA slows and SSA rapidly reaches its minimum value.

According to Eqs. (2) and (3), the rate of SSA decrease for a given time step $(\triangle \mathrm{SSA})$ depends on snow age, snow temperature, temperature gradient and $\mathrm{SSA}_{\text {initial }}$. Based on

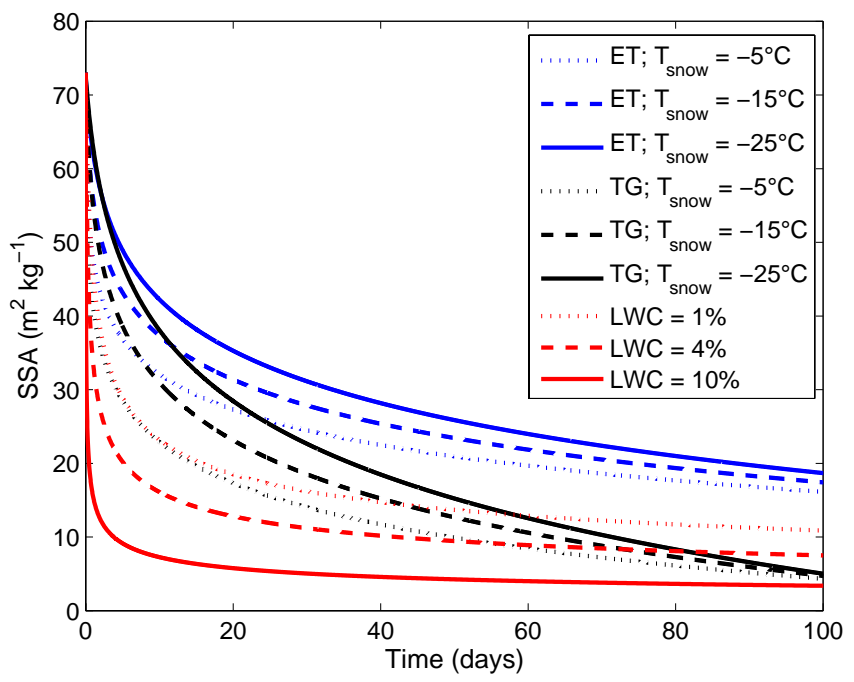

Fig. 2. SSA evolution as a function of the temperature gradient regime $(\mathrm{ET}$ or $\mathrm{TG}$ with $\mathrm{LWC}=0)$ and snow temperature $\left(T_{\text {snow }}\right)$ from Eqs. (2) and (3), as well as a function of liquid water content (LWC) from Eq. (5).

Jacobi et al. (2010), we calculate the $\Delta$ SSA from Eqs. (2) and (3) according to the following:

$\Delta \mathrm{SSA}=\operatorname{SSA}(t+\Delta t)-\operatorname{SSA}(t)$

where $\Delta t$ corresponds to the time step $(0.5 \mathrm{~h})$. The $\Delta \mathrm{SSA}$ is then subtracted from the model's previous SSA value. Jacobi et al. (2010) used a temperature gradient threshold ( $\mathrm{TG}_{\text {threshold }}$ ) of $15 \mathrm{~K} \mathrm{~m}^{-1}$ to distinguish between ET and TG conditions, which will be evaluated in this study. Taillandier et al. (2007) also suggested a minimum value for SSA, because the logarithmic equation for SSA can lead to unrealistic low values. The minimal SSA value is set to $8.0 \mathrm{~m}^{2} \mathrm{~kg}^{-1}$, as proposed by Taillandier et al. (2007).

Nevertheless, the parameterization reported by Taillandier et al. (2007) does not take into account metamorphism during wet snow conditions. The equation of Brun (1989), derived from experimental measurements, provides a way to simulate the evolution of snow grain volume under wet snow conditions with respect to the liquid water content of the snowpack. The equation of Brun (1989) can be expressed with optical radius growth $\left(\Delta R_{\mathrm{opt}}\right)$ :

$\Delta R_{\mathrm{opt}}=\frac{C_{1}+C_{2} \mathrm{LWC}^{3}}{R_{\mathrm{opt}}^{2} \cdot 4 \pi}$,

where $C_{1}$ and $C_{2}$ are empirical coefficients $\left(\mathrm{C}_{1}=1.1 \times\right.$ $\left.10^{-3} \mathrm{~mm} \mathrm{day}^{-1}, C_{2}=3.7 \times 10^{-5} \mathrm{mmday}^{-1}\right)$ and $\mathrm{LWC}$ is the liquid water content in mass percentage. Note that in the experiment of Brun (1989), the empirical relationship was based on the volume equivalent sphere deduced from the measured mean convex snow grain radius, which is a definition closely related to the SSA. Figure 2 shows that the 
SSA decrease is more pronounced when LWC increases in the snowpack. In this study, when the CLASS liquid water content is greater than zero, the model-derived SSA value is converted into its equivalent $R_{\text {opt }}$ using Eq. (1) in order to apply Eq. (5), and then reconverted to SSA. Furthermore, because the LWC distribution is not homogeneous within the snowpack, even though CLASS uses a single LWC value for the whole snowpack, here the LWC is first distributed in the top $10 \mathrm{~cm}$. If the LWC in the top $10 \mathrm{~cm}$ is greater than $10 \%$ in mass, the excess water is distributed to the rest of the snowpack. The $10 \%$ limit can thus be considered as the water retention capacity. This value was chosen because $10 \%$ in mass is the value where, in the experiment of Brun (1989), LWC reaches the irreducible water content and percolation occurs, leading to a saturation of grain growth rate increase for high LWC. However, the liquid water retention capacity of CLASS for the whole snowpack was kept at $4 \%$.

\subsection{Sites and data}

Snowpit measurements were conducted at five sites. Measurements were taken during the winter of 2010-2011 at the first two sites, which were located in an open mid-latitude northern environment. The sites were at the Site interdisciplinaire de recherche en environnement extérieur (SIRENE) experimental station at the Université de Sherbrooke $\left(45.37^{\circ} \mathrm{N}, 71.92^{\circ} \mathrm{W}\right)$ and at St-Romain $\left(45.45^{\circ} \mathrm{N}, 71.02^{\circ} \mathrm{W}\right.$; $80 \mathrm{~km}$ northeast of Sherbrooke) in Québec, Canada. Mean January temperature at Sherbrooke is $-11.9^{\circ} \mathrm{C}$ and the cumulated precipitation is $294.3 \mathrm{~cm}$ of snowfall, generally from November to April (National Climate Data, Environment Canada). Temperatures are generally slightly colder at St-Romain and cumulated snowfall higher because of the higher altitude $(\approx 150 \mathrm{~m}$ over Sherbrooke). Two other sites were located close to the Churchill Northern Study Centre $\left(58.73^{\circ} \mathrm{N}, 93.81^{\circ} \mathrm{W}\right)$ in Manitoba, Canada: one in an arctic dry fen (tundra) and the other in a taiga environment (black spruce forest). Churchill has a subarctic climate with a mean January temperature of $-26.7{ }^{\circ} \mathrm{C}$ and accumulated snowfall of $191 \mathrm{~cm}$, generally from October to May (National Climate Data, Environment Canada). The data were collected at these two sites during the Canadian CoReH20 Snow and Ice (CAN-CSI) campaign in the winter of 2010, which included four periods of intensive field sampling (January, February, March, and April). Further details of the campaign are provided in Derksen et al. (2012). The fifth and final site is the meteorological research station Col de Porte (CDP; $\left.45.17^{\circ} \mathrm{N}, 5.46^{\circ} \mathrm{E}\right)$, near Grenoble, France, in the French Alps at an elevation of $1325 \mathrm{~m}$. The daily average mean temperature for January is $-1.63^{\circ} \mathrm{C}$ and the mean total cumulated snowfall from December to April is $557 \mathrm{~cm}$. Measurements for this last site were carried out during the winter of 2009-2010 (see Morin et al., 2013, 2012 for more details).
At the first four sites, SSA profiles were taken at a vertical resolution of $5 \mathrm{~cm}$. The SSA was measured with the shortwave InfraRed Integrating Sphere (IRIS) system (Montpetit et al., 2012), based on the principle described by Gallet et al. (2009), which exploits the relationship between the SWIR snow reflectance and the SSA (Kokhanovsky and Zege, 2004). The density was measured with a $185 \mathrm{~cm}^{3}$ density cutter, and the samples were weighed with a $100 \mathrm{~g}$ Pesola light series scale with an accuracy of $1 \mathrm{~g}$. The temperature was measured with a Traceable 2000 digital temperature probe. Liquid water content of snow was also measured with the Snow Fork (Toikka Engineering Ltd., Espoo, Finland) at the Churchill arctic fen site during wet conditions on 13 and 16 April 2010. At the Col de Porte site (the fifth site), 16 SSA profiles were taken using the Dual Frequency Integrating Sphere for Snow SSA instrument (DUFISSS: Gallet et al., 2009), also based on the relationship between the SWIR reflectance and the SSA. Note that from late February onwards, warm conditions led to several snowmelt events, which caused a significant decrease in the snow SSA values. Hence, a distinction was made between dry snow conditions at Col de Porte (7 sets of data from 6 January to 16 February) and wet snow conditions ( 9 sets of data from 25 February to 20 April). The total snow depth and snow density profiles were also measured (Morin et al., 2013) and ultrasonic snow depth observations were acquired at SIRENE and Col de Porte.

NARR data (Mesinger et al., 2006) (2 m air temperature and air humidity, precipitation, $10 \mathrm{~m}$ wind speed, surface shortwave and longwave radiation) were used to force the CLASS model at the first four sites. Langlois et al. (2009) show that the NARR product delivers reliable input data for snowpack modeling. Forcing data from the NARR nearest neighbor pixel of each site was employed. As NARR provide data on a three-hour time step, the variables were interpolated to a $30 \mathrm{~min}$ time step, except for precipitation, which maintained a three-hour interval. To initialize the starting conditions, the CLASS model was run starting the year prior to the winter in this study: from 1 October 2009 to 1 June 2011 at SIRENE and St-Romain; from 1 October 2008 to 1 June 2010 at the two Churchill sites. At the Col de Porte site, meteorological variables (air temperature, humidity, windspeed, precipitation and incoming shortwave and longwave radiation) recorded with an hourly time resolution throughout the snow season of 2009-2010 (from 20 September 2009 to 10 May 2010) were interpolated to a $30 \mathrm{~min}$ time-step and used to drive the CLASS model (see Morin et al., 2012 for more details on the Col de Porte meteorological data). 

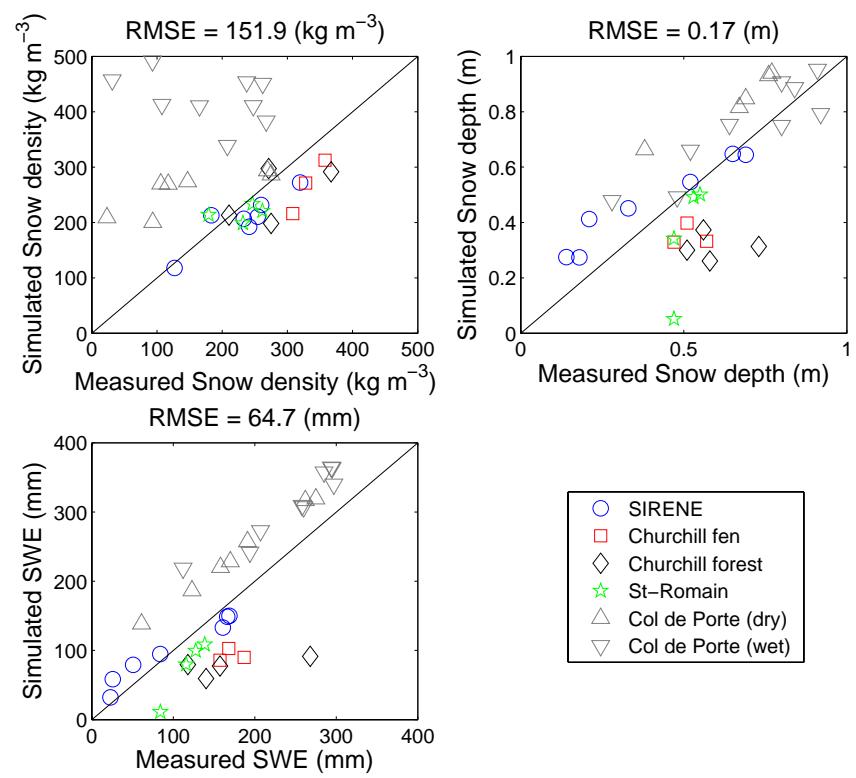

Fig. 3. Comparison of CLASS simulated snow properties with field measurements at different sites. Dry and wet sites at Col de Porte are separately indicated (see legend).

\section{Results}

\subsection{CLASS snow parameter evaluation}

First, an analysis of the one-layer CLASS snow model simulations was conducted. Simulated snow density, total snow depth and SWE were compared with all measurements taken in snow pits where SSA profiles were measured. Figure 3 shows that the simulation accuracy varies from one site to another. Snow density is generally accurate except at $\mathrm{Col}$ de Porte, where the density was overestimated. The overestimation is probably due to the high densification of snow under wet conditions with CLASS. For snow depth, there is an underestimation for the Churchill sites. Since there were underestimates at both forest and fen sites, NARR precipitation is probably the main cause. In fact, the cumulated NARR precipitation from the beginning of the snow season to the first snowpit measurement in February at the dry fen is lower $(97.1 \mathrm{~mm})$ than the snowpit measured SWE $(157.3 \mathrm{~mm})$. However, other phenomena such as blowing snow and interception by vegetation could lead to differences between the simulated and measured SWE (consequently snow depth as well). Comparisons between continuous ultrasonic snow depth observations at SIRENE and Col de Porte also show that errors in diagnosing precipitation phase at the beginning of the snow season lead to an offset of snow depth (overestimation at SIRENE) (Fig. 4a). This sensitivity to precipitation phase in CLASS is also demonstrated in Langlois et al. (2013). Figure 4b shows that underestimation of melt events at the beginning of the season also lead to positive offset in the snow depth. However, the snow depth RMSE is
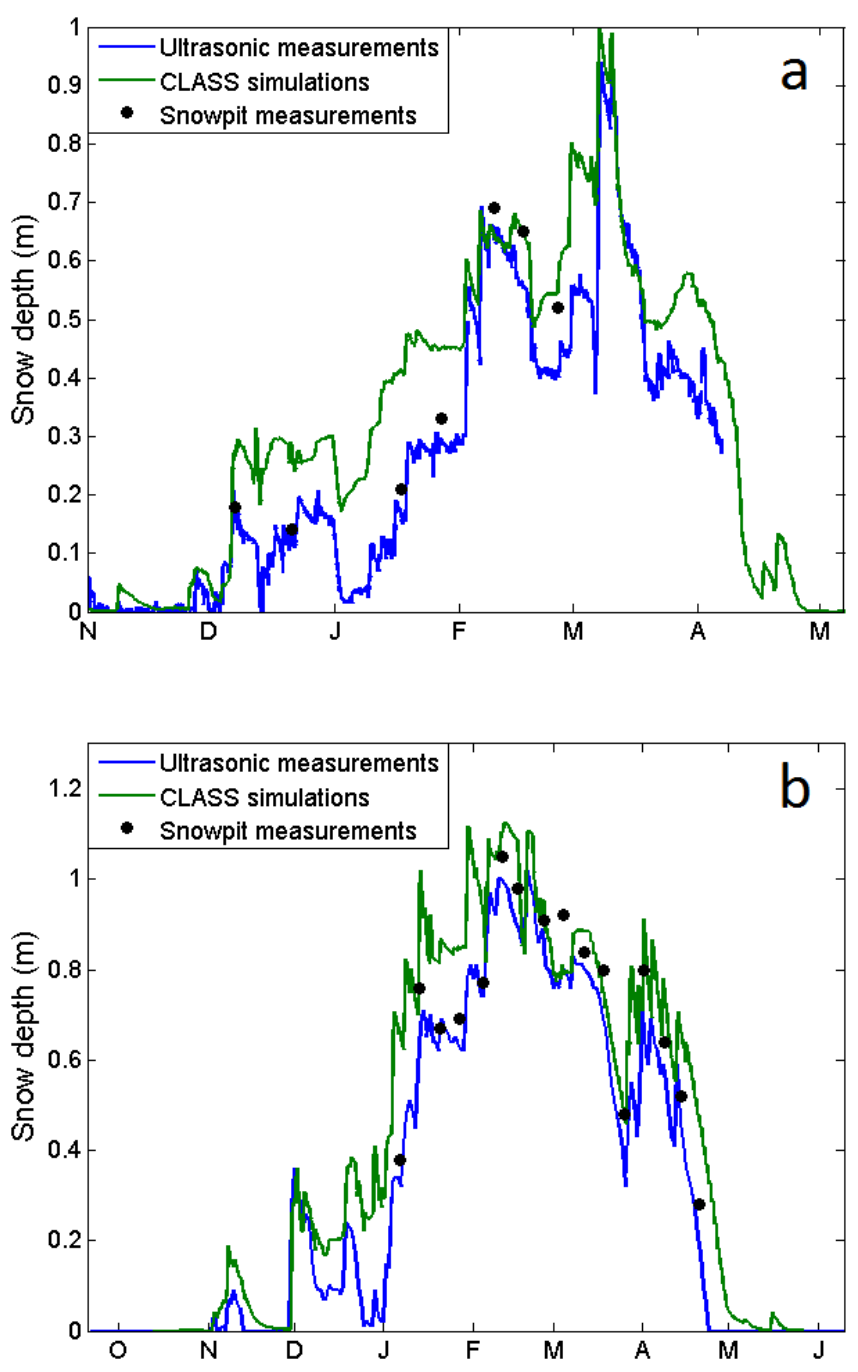

Fig. 4. CLASS snow depth simulations compared with Ultrasonic measurements at (a) SIRENE and (b) Col de Porte. Black dots are the snow depths from snowpit measurements.

comparable to what was found with CLASS 3.1 in the Snow Model Intercomparison Project (Brown et al., 2006). The overall SWE RMSE is $64.7 \mathrm{~mm}$, which is close to what was found in Langlois et al. (2013) between modeled (CRCM) and observed SWE values for northern Québec. There is a good correlation between the measured and simulated SWE for the SIRENE and Col de Porte sites, where there is, however, a consistent overestimation. However, the SWE is underestimated at St-Romain and both Churchill sites.

\subsection{CLASS-SSA model evaluation and validation}

In this study, SSA is considered for the evaluation and validation because measurements of shortwave infrared reflectance of snow are related to SSA (see Sect. 2.2). To evaluate the CLASS-SSA simulations, an analysis of the $\mathrm{TG}_{\text {threshold }}$ was first conducted. However, differences between the simulated 


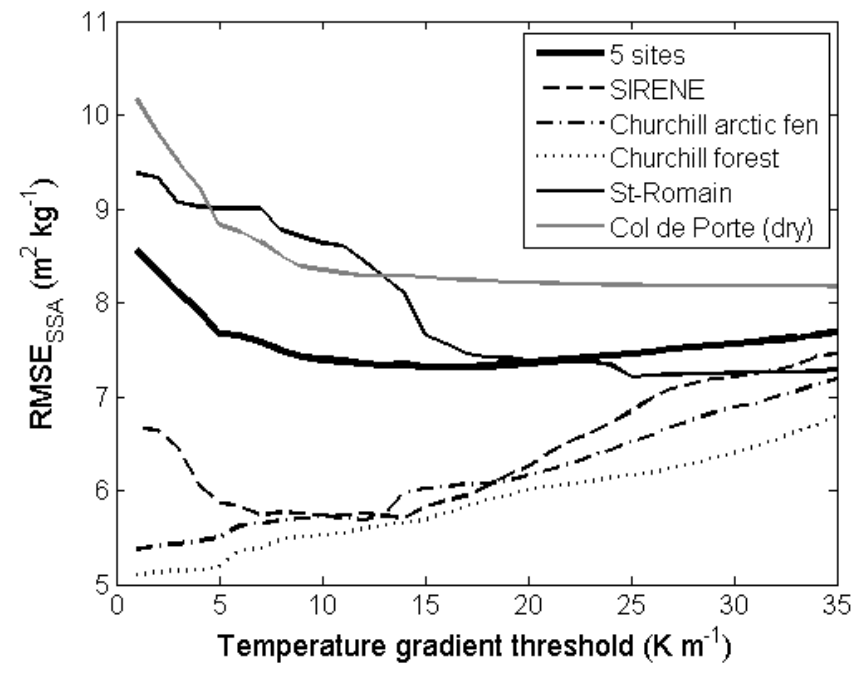

Fig. 5. RMSE $E_{S S A}$ between the measured SSA and the simulated SSA using CLASS-SSA as a function of the temperature gradient threshold ( $\left.\mathrm{TG}_{\text {treshold }}\right)$.

and measured snow depths (Figs. 3 and 4), caused problems when relating measured SSA to its corresponding simulated SSA for a given snow depth in the snowpack. A correction was applied to the measured snow depth in order to match the simulated snow depth; this caused the measured profiles to be stretched or compressed. The root mean square error values between the simulated and measured

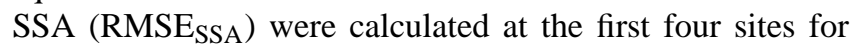
different $\mathrm{TG}_{\text {threshold }}$ values. The Col de Porte site where wet snow metamorphism dominated was excluded because wet metamorphism has a strong influence on SSA evolution that is not related to the $\mathrm{TG}_{\text {threshold. Figure } 5 \text { shows }}$ that, for $\mathrm{TG}_{\text {threshold }}$ values between $10 \mathrm{Km}^{-1}$ and $20 \mathrm{Km}^{-1}$,

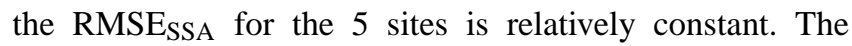
minimum RMSESSA value $\left(7.3 \mathrm{~m}^{2} \mathrm{~kg}^{-1}\right)$ for the 5 sites is $\mathrm{TG}_{\text {threshold }}=16 \mathrm{Km}^{-1}$, which is close to the $15 \mathrm{Km}^{-1}$ value used by Jacobi et al. (2010). This value is also consistent with Taillandier et al. (2007), who proposed that the $\mathrm{TG}_{\text {threshold }}$ should be between $9 \mathrm{Km}^{-1}$ and $20 \mathrm{Km}^{-1}$. The SIRENE site reached a minimum RMSE at $\mathrm{TG}_{\text {threshold }}=14 \mathrm{Km}^{-1}$, whereas the RMSE at both Churchill sites slightly increased

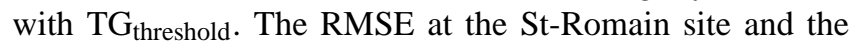
dry snow condition data for the Col de Porte site slightly decreased from $10 \mathrm{~K} \mathrm{~m}^{-1}$ to $25 \mathrm{Km}^{-1}$ before reaching a constant value (Fig. 5).

The minimum RMSE was at $\mathrm{TG}_{\text {threshold }}=16 \mathrm{Km}^{-1}$ and was thus used to simulate SSA with CLASS-SSA at the 5 sites (Fig. 6). Previous studies have generally defined the TG threshold for depth hoar formation between $10 \mathrm{Km}^{-1}$ and $20 \mathrm{~K} \mathrm{~m}^{-1}$ (Taillandier et al., 2007; Colbeck, 1983; Marbouty, 1980). However, it should be noted that the formation of faceted snow crystals has been observed at low growth rates under low gradient thresholds (Domine et al., 2003; Flin and
Brzoska, 2008). Pinzer and Schneebeli (2009) proposed that alternating temperature gradients also leads to formation of rounded grains, similar to those observed in ET metamorphism. However, overall comparisons show good agreement between simulated and measured SSA (Fig. 6). More specifically, the SIRENE and St-Romain results show similar patterns with a gradient from low SSA at the bottom to higher SSA coming from fresh precipitation at the top. Nevertheless, there is a low SSA layer that appeared in mid-December 2010 caused by a melt event. This layer was observed as a melt ice-crust layer of $3 \mathrm{~cm}$ with low SSA (measured with a SWIR camera: Montpetit et al., 2012) during the snowpit measurements, but SSA was not measured with IRIS because it is difficult to extract this kind of snow (i.e., crusts) with the IRIS instrument. For the Churchill sites, both measured and simulated SSA are low near the bottom $(\approx 25 \mathrm{~cm})$, which is related to the formation of depth hoar in the presence of a high temperature gradient. However, the simulated SSA values in the top layers are generally higher than the measurements. This may be due to the underestimation of the snow depth at the beginning of the season causing an underestimation of the relative thickness of the bottom layers with low SSA within the snowpack, which leads to an overestimation of the top layer thickness (Fig. 6c and d). Underestimation of the April 2010 measurements at both sites should, however, be attributed to an underestimation of snow LWC by CLASS during the spring melt, which limited the decrease of simulated SSA by wet metamorphism. In fact, LWC as measured with the Snow Fork instrument on 13 and 16 April at the Churchill arctic fen site suggests a strong underestimation by CLASS ( $0.2 \%$ vs. $3.8 \%$ on 13 April and $1.0 \%$ vs. $15.5 \%$ on 16 April, for CLASS and the Snow Fork, respectively). The issue with LWC is discussed in Sect. 4. The Col de Porte site illustrates the difference between the first seven dry sets of data showing good agreement, and the second period, starting on 25 February, when wet snow becomes predominant in the snowpack, giving a systematic overestimation of the SSA.

The comparison of the simulated SSA values to their corresponding measurements gives a RMSE of $8.0 \mathrm{~m}^{2} \mathrm{~kg}^{-1}$, which represents an error of $42.3 \%$ (Fig. 7). Part of the error could be attributed to the fact that we did not necessarily compare the same snow layers due to different positions between the simulated and measured points. The correction applied to the simulated snow depth profile might be a factor, but the high variability within a SSA profile might also be a source of error. The simulated SSA variations are also strong within the snowpack, mainly for high SSA, where the evolution is faster (see Fig. 2). Considering the mean depthaveraged SSA weighted by the snow layer thickness, the RMSE decreases significantly to $5.1 \mathrm{~m}^{2} \mathrm{~kg}^{-1}$, representing an error of $25.7 \%$. Furthermore, the coefficient of determination $\left(R^{2}\right)$ increases from 0.60 to 0.84 . As mentioned previously, another major source of error corresponds to the influence of wet conditions, as observed at the Col de Porte site 

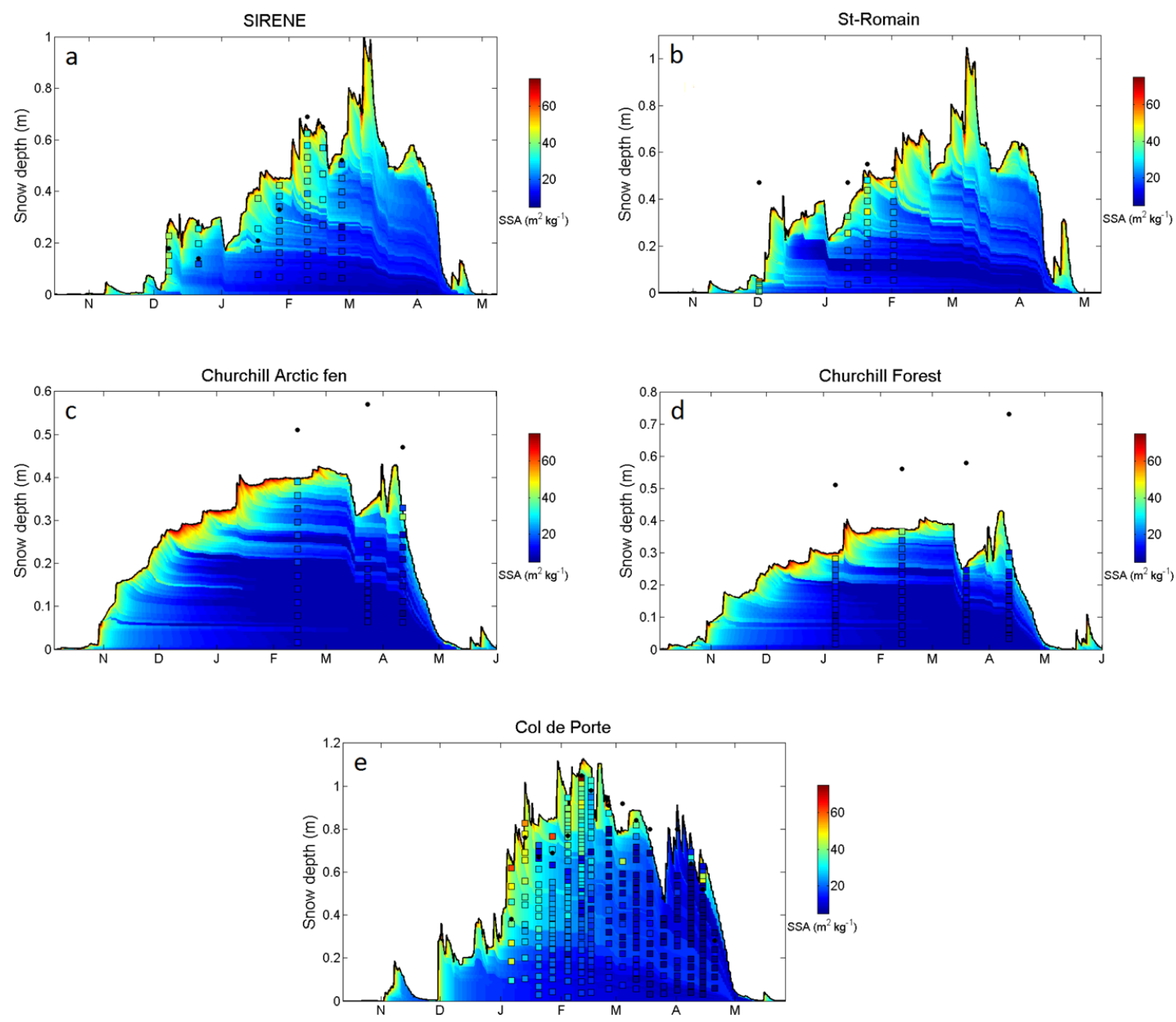

Fig. 6. Seasonal profile of simulated SSA at the five sites, (a) SIRENE, (b) St-Romain, (c) Churchill Arctic fen, (d) Churchill Forest, and (e) Col de Porte), compared to SSA measurements (squares: where the measured SSA profiles were adjusted to the simulated snow depth, see text). The measured profiles are stretched or compressed to fit with simulated snow depth. Black dots correspond to the measured snow depths.

after the mid-season. In fact, by removing data for this wet period, the depth-averaged RMSE decreases to $4.1 \mathrm{~m}^{2} \mathrm{~kg}^{-1}$ $(17.5 \%)$. As mentioned in Morin et al. (2013), even with a multi-layer model, limitations on the precision of LWC simulations exacerbate the difficulty of modeling snow grain evolution under wet conditions. The weakness of the model under wet snow conditions will be analyzed below in the Discussion (Sect. 4). The SSA at St-Romain and at Col de Porte (dry snow period) are underestimated by the model, while at the Churchill sites SSA is slightly overestimated due to the high simulated SSA in the top layers (Fig. 6c and d).

\section{Discussion}

The simulation of a stratified phenomenon such as SSA using a one-layer snow model such as CLASS requires certain assumptions and simplifications of the physics within the snowpack. These assumptions may induce errors in estimates of the SSA evolution. Here, we discuss the different elements that may impact the precision of the model and how they may influence the estimates. It is thus possible to identify the conditions under which CLASS-SSA is more limited and propose possible improvements. We then consider the proposed model's application, mainly in the context of passive microwave simulations.

\subsection{Sources of errors}

An assumption made in the CLASS-SSA approach is that the temperature profile of the snowpack is linear. In general, the temperature variations will be larger in the top layers that are responding to the variations in air temperature, while the bottom layers are less affected as the air temperature fluctuations do not reach these layers because of the low snow thermal conductivity 

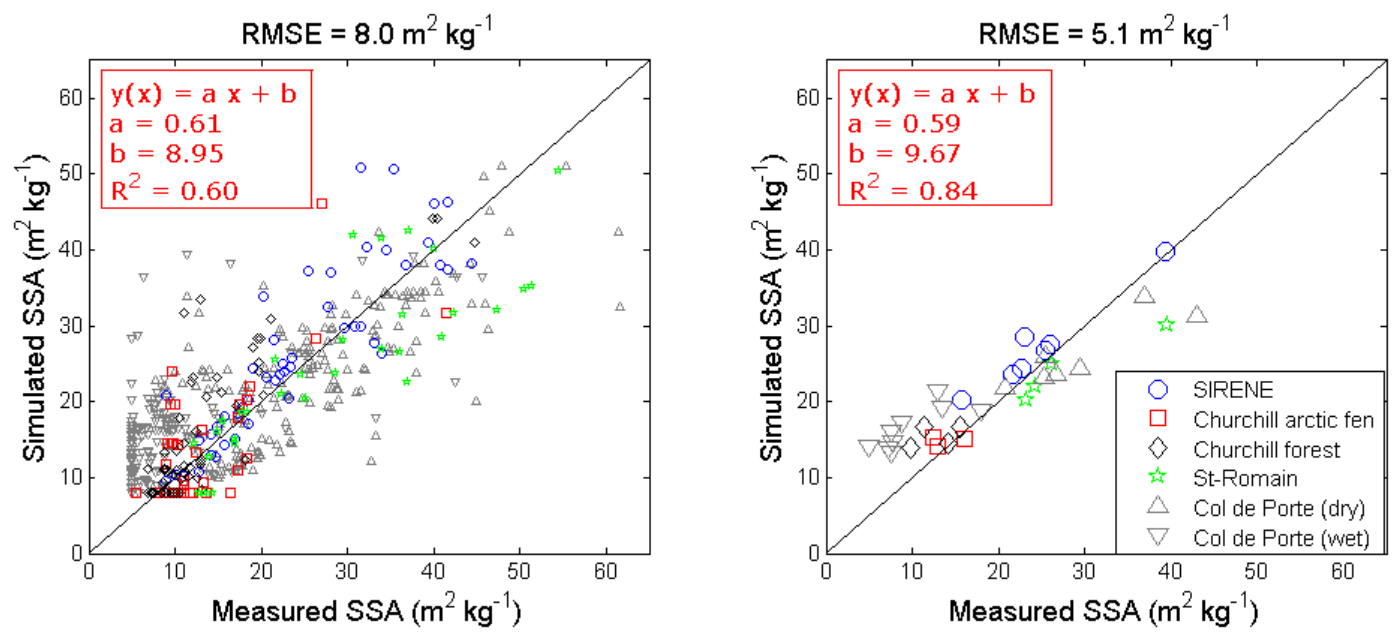

Fig. 7. Measured vs. simulated SSA comparison (left panel shows all points; right panel shows the one-layer average). The RMSE in averaged SSA (right panel) without the wet points is $4.1 \mathrm{~m}^{2} \mathrm{~kg}^{-1}$.

(Armstrong and Brun, 2008; Vionnet et al., 2012). Hence, in cold weather like in Churchill, the linearity of the temperature profiles is likely to induce underestimated snow layer temperatures. This phenomenon could also partly explain why the SSA of top layers at both Churchill sites is overestimated, considering that the SSA decrease is more pronounced with higher snow temperatures. Furthermore, the linearity of the temperature gradient would generally underestimate the local temperature gradient in the top layers and overestimate the local temperature gradient in the bottom layers. However, in the north during winter, this diurnal temperature cycle is generally in most cases less pronounced than over temperate or mountainous regions (Leathers et al., 1998). Thus, using a linear gradient throughout a dry and relatively shallow snowpack (below about 1 to $1.5 \mathrm{~m}$ depth) appears as a satisfactorily hypothesis in most cases over northern areas. Kondo and Yamazaki (1990) demonstrated that a linear temperature profile can be successfully employed in a snowmelt model.

As shown through the wet metamorphism simulation, CLASS-SSA is limited by the modeling of snow parameters in CLASS. Hence, the use of a one-layer model giving a LWC for the entire snowpack becomes a limitation. Furthermore, there might be an underestimation of LWC by CLASS. Measurements of LWC with the Snow Fork instrument at the Churchill arctic fen site suggests a strong underestimation by CLASS. Moreover, raising the limit of the simulated snowpack water retention capacity from $4 \%$ to $10 \%$ did not improve the simulated LWC and the SSA calculation under wet conditions in Col de Porte because the CLASS LWC rarely reaches the retention capacity. Part of the problem was, however, resolved by distributing the LWC mostly in the top layers, but the SSA evolution under wet conditions remains a weakness. Table 1 shows that the bias is significantly reduced when wet metamorphism is modeled with
Table 1. SSA bias and RMSE for Col de Porte wet snow condition data for different configurations of CLASS-SSA wet metamorphism.

\begin{tabular}{lrr}
\hline Model Configurations & RMSE $\left(\mathrm{m}^{2} \mathrm{~kg}^{-1}\right)$ & Bias $\left(\mathrm{m}^{2} \mathrm{~kg}^{-1}\right)$ \\
\hline No wet metamorphism & 15.9 & 13.4 \\
Uniform LWC (CLASS) & 12.6 & 10.1 \\
LWC distributed in the top 10 cm & 9.4 & 6.8 \\
(CLASS-SSA configuration) & & -2.6 \\
Drastic increase of LWC & 6.7 & \\
(if LWC $>0$ then LWC $=10 \%)$ & & \\
\hline
\end{tabular}

snowpack liquid water distributed in the top $10 \mathrm{~cm}$ at the $\mathrm{Col}$ de Porte wet sites compared to a wet metamorphism considering a uniform LWC or compared to no wet metamorphism. We also tested simulations by drastically increasing the total LWC artificially in CLASS (if LWC $>0$ then $\mathrm{LWC}=10 \%$ ); such conditions significantly reduced the simulated SSA, as expected, with a bias of $-2.6 \mathrm{~m}^{2} \mathrm{~kg}^{-1}$ for Col de Porte wet snow condition data (Table 1). This last case confirms that the problem comes from an underestimation of LWC in CLASS under warm conditions.

Snow depth errors from CLASS might also impact CLASSSSA simulations. In fact, as shown for both Churchill sites (Fig. 6c and d), a bias in snow precipitation can impact the representation of the thickness of a given snow layer. Thus, in this study, part of the SSA error could be related to uncertainties in the NARR precipitation data (Langlois et al., 2009).

Other phenomena not parameterized in the CLASS snow model, such as blowing snow, could influence the simulated snow depth (Liston and Hiemstra, 2011). In open areas (four of our five sites), strong wind shear stress could have exceeded the snow particle resistance to dislocation ( $\mathrm{Li}$ and Pomeroy, 1997). Hence, a less cohesive top snow layer with lower SSA could be removed almost completely in an open 


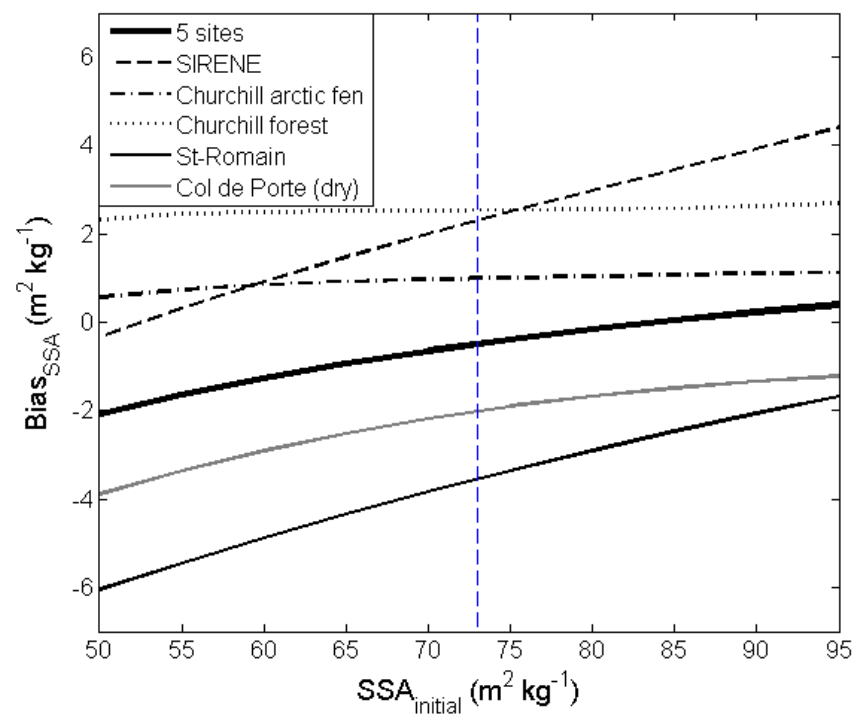

Fig. 8. Bias between the measured SSA and the simulated SSA using CLASS-SSA as a function SSA $_{\text {initial }}$ (the vertical dotted blue line represents the $S_{S A} A_{\text {initial }}$ set in CLASS-SSA at $73.0 \mathrm{~m}^{2} \mathrm{~kg}^{-1}$ ).

arctic region like Churchill (Baggaley and Hanesiak, 2005). Furthermore, the snow thermal conductivity strongly varies between the tundra, where the snowpack has a high conductivity due to hard wind slabs, compared to taiga and forest snowpacks, which have three to four times lower thermal conductivity due to lower wind compaction and depth hoar development (see Gouttevin et al., 2012). These differences impact the snow temperature and temperature gradient but are not represented in CLASS-SSA.

In the CLASS-SSA model, the SSA $_{\text {initial }}$ value is fixed at $73.0 \mathrm{~m}^{2} \mathrm{~kg}^{-1}$. This value was chosen based on freshly fallen snow SSA measurements (sampled maximum $24 \mathrm{~h}$ after snowfall) from methane adsorption by Domine et al. (2007). However, this study shows a range of 33.1 to $155.8 \mathrm{~m}^{2} \mathrm{~kg}^{-1}$ with a standard deviation of $\pm 26.2 \mathrm{~m}^{2} \mathrm{~kg}^{-1}$ based on $63 \mathrm{sam}$ ples. Freshly fallen snow SSA is rarely modeled as it depends on the type of solid precipitation, which depends on the meteorological conditions (air temperature, wind, type of clouds, atmospheric stratification) when the snowflake is formed. Domine et al. (2007), however, proposed freshly fallen snow SSA values based on four types of fresh snow that can be related to density. As CLASS calculates the fresh snow density from the air temperature using the equation from Hedstrom

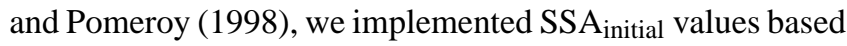
on the Domine et al. (2007) relationship. However, this implementation did not change the results significantly: a slight increase in RMSE from 8.0 to $8.3 \mathrm{~m}^{2} \mathrm{~kg}^{-1}$ was found. Figure 8 shows that $\mathrm{SSA}_{\text {initial }}$ has a relatively low impact on simulations. The sensitivity to $\mathrm{SSA}_{\text {initial }}$ values appears to be more important for the snowpack where measurements were taken mostly at the beginning of the season (SIRENE and St-Romain). A precise dynamic parameterization of freshly fallen SSA could probably improve the results, mostly for snow with high SSA at the beginning of the snow season.

\subsection{Comparison with other models}

Despite the above simplifications, the CLASS-SSA model simulates SSA with a reasonable accuracy for a wide range of snow types. Our RMSE of $8.1 \mathrm{~m}^{2} \mathrm{~kg}^{-1}$ (Fig. 7) is comparable to the result obtained at $\mathrm{Col}$ de Porte by Morin et al. (2013) from internal computation of the optical radius in Crocus $\left(6.37 \mathrm{~m}^{2} \mathrm{~kg}^{-1}\right)$ and the method of Domine et al. (2007) based on the density and snow type $\left(8.08 \mathrm{~m}^{2} \mathrm{~kg}^{-1}\right)$. Snow data from the 2010 winter season at Col de Porte provide a unique and very accurate time series of SSA measurements (Morin et al., 2013). Figure 9 shows a comparison of temporal snowpack averaged SSA values at Col de Porte for CLASS-SSA, the Crocus model (Morin et al., 2013), and the measurements. When the snowpack is dry, both models underestimate the SSA. On 25 February and after, when wet conditions occurred, CLASS-SSA overestimates the SSA due an underestimation of the snowpack LWC, while Crocus still underestimates the SSA. For this dataset, CLASS-SSA simulations seem comparable to or better than Crocus in dry conditions. However, in wet conditions, Crocus better simulates the decrease in SSA as LWC increases (Fig. 9). Hence, Crocus seems to better capture the dynamics of the SSA evolution. Note that Jacobi et al. (2010) obtained, from 162 snow SSA measurements at a taiga site, an RMSE of $8.6 \mathrm{~m}^{2} \mathrm{~kg}^{-1}$ with the implementation of the Taillandier et al. (2007) approach within Crocus, whereas the implementation of Domine et al. (2007) resulted in a RMSE of $16.2 \mathrm{~m}^{2} \mathrm{~kg}^{-1}$ (the results were highly affected by the underestimation of snow density by Crocus).

\section{3 $R_{\text {opt }}$ analysis for MESM}

In the context of using the simulated SSA to assimilate microwave brightness temperatures $\left(T_{\mathrm{B}}\right)$, we now examine the impact of errors generated by the proposed approach in terms of $T_{\mathrm{B}}$ error. As mentioned in Sect. 1, the DMRT MESM calculates $T_{\mathrm{B}}$ from $R_{\mathrm{opt}}$ derived from SSA. Figure 10 shows the comparison between $R_{\mathrm{opt}}$ derived from measured SSA and $R_{\text {opt }}$ derived from simulated SSA. As the relationship between SSA and $R_{\mathrm{opt}}$ is not linear (Eq. 1), we see that for individual points (Fig. 10, left panel), the differences between simulated and measured $R_{\text {opt }}$ are more important for larger grains. This is caused by the fact that for low SSA, a given variation of SSA leads to a larger change in the simulated $R_{\text {opt }}$ (a change of SSA from 10 to $8 \mathrm{~m}^{2} \mathrm{~kg}^{-1}$ leads to a change in $R_{\text {opt }}$ from 0.327 to $0.409 \mathrm{~mm}$ ). $R_{\text {opt }}$ is then much more sensitive to error in SSA for larger grains. This also partly explains why the error for wet snow condition data in Col de Porte is large. For mean $R_{\mathrm{opt}}$ values over the snowpack, there is a RMSE of $0.043 \mathrm{~mm}$ and $R^{2}$ of 0.84 , comparable to SSA results, if the wet snowpacks are excluded. There is, 


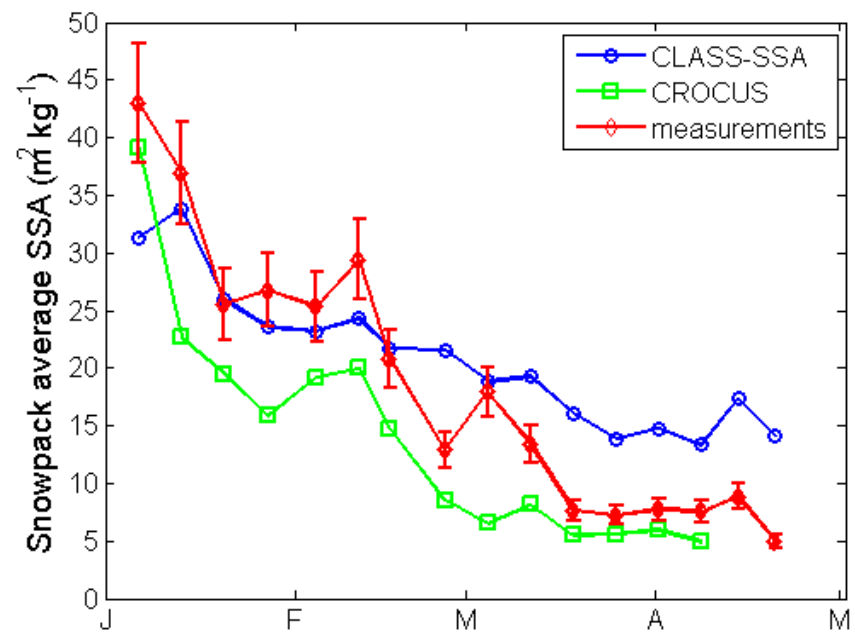

Fig. 9. Snowpack-averaged SSA evolution with time at Col de Porte for CLASS-SSA, Crocus (Morin et al., 2013) and the measurements. The last Crocus value was excluded because the simulations give no snow on ground. Error bars on measurements are the measurements accuracy (12\%: Gallet et al., 2009).

however, a small positive bias of $0.034 \mathrm{~mm}$, mainly caused by the strong influence of large grains in the averaging.

Moreover, the density stratification is another parameter that should be considered when modeling the radiative transfer within the snowpack (e.g., Picard et al., 2012). In our case, the densification routine in CLASS-SSA is only used to calculate the depth and the position of every snow layer, and not necessarily to calculate a precise density. The simulated densities might differ from real densities. An example is the decrease of densification at the bottom snow layer when depth hoar formation occurs that is not taken into account in the SSA offline model. The correction of densities in the top layers (see Sect. 2.1) might also lead to low densities in the top layers. Here, to attenuate the effects of these simplifications in the $T_{\mathrm{B}}$ simulations, we consider a bulk snowpack characterized by an effective snow grain effective radius $R_{\text {eff }}$ calculated from the averaged $R_{\text {opt }}$ following the form suggested by Kontu and Pulliainen (2010):

$R_{\mathrm{eff}}=a\left[1-\exp \left(-b R_{\mathrm{opt}}\right)\right]$

where $a=1.3$ and $b=4.7$. These empirical parameters were fitted from simulations using averaged $R_{\text {opt }}$ derived from measured SSA compared to ground-based radiometric measurements, except for the bulk snowpack (see Roy et al., 2013).

Simulations with the DMRT-ML (Picard et al., 2013) were conducted to analyze the effect of the $R_{\mathrm{opt}}$ error on $T_{\mathrm{B}}$ simulations. The $T_{\mathrm{B}}$ simulations were conducted employing single-layer averaged $R_{\text {eff }}$ values (Eq. 6) \pm the derived RMSE of $R_{\mathrm{opt}}( \pm 0.043 \mathrm{~mm})$. Considering a snowpack of $0.5 \mathrm{~m}$ with a bulk density of $250 \mathrm{~kg} \mathrm{~m}^{-3}$, an error of $0.043 \mathrm{~mm}$ in $R_{\mathrm{opt}}$ leads to maximum variations of $T_{\mathrm{B}}$ of the order of $\pm 23.3 \mathrm{~K}$ at $36.5 \mathrm{GHz}$ and $\pm 2.7 \mathrm{~K}$ at $18.7 \mathrm{GHz}$. We thus see the high sensitivity of $36.5 \mathrm{GHz}$ to grain size, given an error that could be significant in some cases (high depth hoar layer), while the proposed simple approach can be applied for $T_{\mathrm{B}}$ simulations at $18.7 \mathrm{GHz}$ with acceptable accuracy. Such a sensitivity analysis would benefit from further development as many combinations of snowpack parameters and conditions could occur.

\subsection{Model applications}

The simulation of snowpack parameters, such as SWE, at individual sites using an operational land-surface scheme designed for use in large-scale climate models could include large errors, as illustrated in Fig. 3. These errors could result from uncertainties in the meteorological forcing data, model parameters, as well as the nonlinearity and scaling effects of the processes modeled (e.g., Andreadis et al., 2008). The proposed model opens opportunities to couple CLASS with MESM for improving SWE estimates. Data assimilation offers the potential to merge information on snow variables from satellite observations and land-surface model simulations. CLASS-SSA was developed mainly for passive microwave $T_{B}$ assimilation in CLASS to improve estimates of snow parameters. The model employed in this study provides a good estimate or "first guess" of the snow grain size and a description of the snow type at a given time during the snow season. Inversion approaches, where parameters (snow depth, snow density) are retrieved by minimizing the differences between simulated and measured brightness temperatures (Langlois et al., 2012; Vachon et al., 2010; Pardé et al, 2007) will benefit from SSA simulations by taking into account the important effect of snow metamorphism on the microwave signal. This "first guess" methodology could also be used as a state initial condition in more complex data assimilation system approaches (Toure et al., 2011; Durand et al., 2009; Reichle, 2008) because the grain-size parameterization is no longer the dominant source of uncertainty. Grain size could still be considered as one of many sources of uncertainty, but with known likely error or variation. Hence, the CLASS-SSA model could be applied to improve SWE estimates at large scales from satellite-borne passive microwave information. From this perspective, as mentioned previously (Sect. 4.3), attention needs to be paid to the effect of the conversion of SSA to $R_{\mathrm{opt}}$ on the uncertainty related to the grain size simulation that depends on the type of grains. In fact, considering Eq. (1), errors in SSA with large grains (low SSA, such as depth hoar) will lead to higher variation of $R_{\text {opt }}$ than for smaller grains (high SSA) (see Morin et al., 2013).

The proposed methodology could also be implemented for a hydrology land-surface scheme (HLSS), such as the one developed within the framework of Environment Canada's community environmental modeling system, MESH. MESH evolved from the WATCLASS model that links a hydrological routing model (WATFLOOD) (Pietroniro et al., 2006) to 

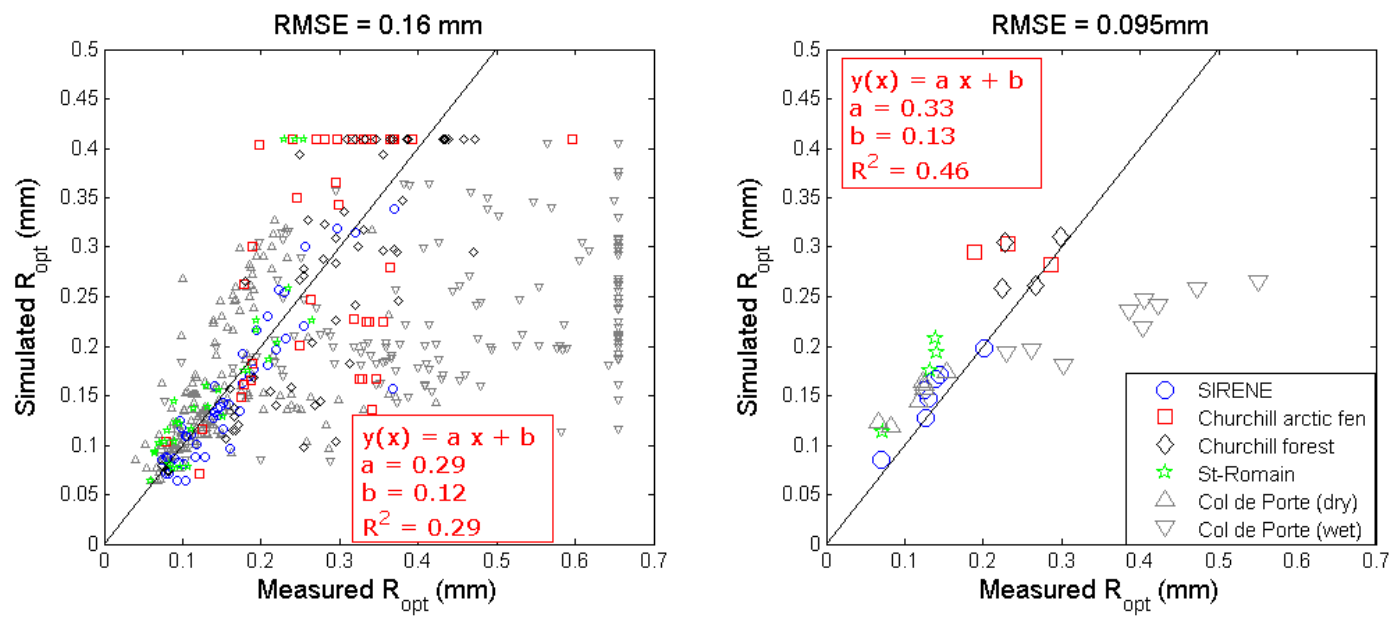

Fig. 10. Measured vs. simulated $R_{\text {opt }}$ derived from SSA (Eq. 1) comparison (left panel shows all points; right panel shows the one-layer average). The RMSE in averaged $R_{\text {opt }}$ (right panel) without the wet points is $0.043 \mathrm{~mm}$.

the Canadian LAnd Surface Scheme (CLASS) discussed in this paper. It is used as a basis for coupling horizontal surface hydrology (river routing) with both weather and climate atmospheric models (see discussion by Teutschbein and Seibert, 2010).

Furthermore, snow surface albedo (mostly in the infrared) is driven by snow grain size. Hence, the use of SSA estimated with CLASS-SSA could lead to improved estimates of snowpack albedo, which are derived from a physically-based model. Pure snow albedo (no impurities) could be related to the SSA using a simple optical equation model suggested by Kokhanovsky and Zege (2004). Based on the simple radiative transfer model of Gardner and Sharp (2010), an error of $8.0 \mathrm{~m}^{2} \mathrm{~kg}^{-1}$ in SSA leads to an uncertainty in the broadband albedo calculation of around $\pm 3 \%$ for small grains $\left(30 \mathrm{~m}^{2} \mathrm{~kg}^{-1}\right)$ to around $6 \%$ for large grains $\left(10 \mathrm{~m}^{2} \mathrm{~kg}^{-1}\right)$. It should be noted that the grains at the top of the snowpack that drive the broadband surface albedo are generally smaller (mostly in dry conditions) and thus less affected by grain uncertainty.

\section{Conclusions}

This study analyzes the coupling of a SSA evolution model with a one-layer snow model from the Canadian LAnd Surface Scheme (CLASS). The simulated SSA values were compared with a unique SSA database for five different sites, representing four different climatic environments, including a wide range of snow types. Based on the SSA decrease due to snow aging in snow layers (Taillandier et al., 2007), the CLASS-SSA model is an offline multi-layer parameterization driven by CLASS single-layer snow model outputs. The CLASS-SSA model also considers wet metamorphism, using the equation of Brun (1989) based on the liquid water content of snow.
Despite the limits of a simple one-layer snow model, it provides a SSA estimate with an overall RMSE of $8.0 \mathrm{~m}^{2} \mathrm{~kg}^{-1}$ for individual layers, and a depth-averaged RMSE of $5.1 \mathrm{~m}^{2} \mathrm{~kg}^{-1}$ for the snowpack SSA. The model, however, shows weaknesses in the wet snow metamorphism regime, which is mostly due to a low bias in the snow model simulations of LWC within the snowpack.

The proposed implementation of the SSA model in an offline mode and driven by a one-layer snow model offers a simple, computationally efficient and versatile approach. It would not be difficult to implement for other models as it only needs six basic inputs that are normally available from snow models (snow depth, SWE, snow density, LWC, soilsnow interface temperature, and air temperature). This approach is thus applicable for other one-layer snow models (Turcotte et al., 2007; Bélair et al., 2003), and also for multilayer models where SSA is not explicitly modeled, such as the Snow-Atmosphere-Soil Transfer (SAST) energy balance snow physics model (Sun et al., 1999).

Future work will evaluate the use of these SSA simulations for satellite passive microwave brightness temperature assimilations and surface snow albedo calculations.

Acknowledgements. The authors would like to thank the National Sciences and Engineering Research Council of Canada (NSERC) and Environment Canada for their financial support. All of our colleagues who helped us during the field campaigns in France and Canada are also gratefully acknowledged. We thank Samuel Morin, (Météo-France - CNRS, CNRM-GAME/Centre d'Études de la Neige), for providing the Col de Porte dataset and valuable suggestions on the manuscript. We thank Diana Verseghy (Climate Processes Section, Environment Canada) for providing the CLASS model code. 
We also thank Ghislain Picard and Florent Domine for their helpful comments and the two reviewers who helped to improve the quality of the manuscript.

Edited by: F. Dominé

\section{References}

Adams, E. and Sato, A.: Model for effective thermal conductivity of a dry snow cover composed of uniform ice spheres, Ann. Glaciol., 18, 300-304, 1993.

Andreadis, K. M., Liang, D., Tsang, L., Lettenmaier, D. P., and Josberger, E. G.: Characterization of errors in a coupled snow hydrology microwave emission model, J. Hydrometeorol., 9, 149$164,2008$.

Aoki, T., Kuchiki, K., Niwano, M., Kodama, Y., Hosaka, M., and Tanaka, T.: Physically based snow albedo model for calculating broadband albedos and the solar heating profile in snowpack for general circulation models, J. Geophys. Res., 116, D11114, doi:10.1029/2010JD015507, 2011.

Armstrong, R. and Brun, E.: Snow and climate: physical processes, surface energy exchange and modeling, Cambridge University Press, Cambridge, 2008.

Arnaud, L., Picard, G., Champollion, N., Domine, F., Gallet, J. C., Lefebvre, E., Fily, M., and Barnola, J. M.: Measurement of vertical profiles of snow specific surface area with a $1 \mathrm{~cm}$ resolution using infrared reflectance: instrument description and validation, J. Glaciol., 57, 17-29, 2011.

Baggaley, D. G. and Hanesiak, J. M.: An empirical blowing snow forecast technique for the Canadian arctic and the Prairie provinces, Weather Forecast., 20, 51-62, 2005.

Bartelt, P. and Lehning, M.: A physical SNOWPACK model for the Swiss avalanche warning, Part I: Numerical model, Cold region Science and Technology, 35, 123-145, 2002.

Bartlett, P. A., MacKay, M. D., and Verseghy, D. L.: Modified snow algorithms in the Canadian land surface scheme: model runs and sensitivity analysis at three boreal forest stands, Atmos. Ocean, 44, 207-222, 2006.

Belair, S., Brown, R., Mailhot, J., Bilodeau, B., and Crevier, L.: Operational implementation of the ISBA land surface scheme in the Canadian regional weather forecast model. Part II: Cold season results, J. Hydrometeorol., 4, 371-386, 2003.

Bougamont, M., Bamber, J. L., and Greuell, W.: A surface mass balance model for the Greenland ice sheet, 110, 2003-2012, 2005.

Brown, R., Bartlett, P., MacKay, M., and Verseghy, D.: Evaluation of snow cover in CLASS for SnowMIP, Atmos. Ocean, 44, 223 238, 2006.

Brucker, L., Picard, G., Arnaud, L., Barnola, J.-M., Schneebeli, M., Brunjail, H., Lefebvre, E., and Fily, M.: Modelling time series of microwave brightness temperature at Dome C, Antarctica, using vertically resolved snow temperature and microstructure measurements, J. Glaciol., 57, 171-182, 2011.

Brun, E.: Investigation on wet-snow metamorphism in respect of liquid-water content, Ann. Glaciol., 13, 22-26, 1989.

Brun, E., David, P., Suduland, M., and Brunot, G.: A numerical model simulate snow-cover stratigraphy for operational avalanche forecasting, J. Glaciol., 38, 14-22, 1992.

Cabanes, A., Legagneux, L., and Domine, F.: Rate of evolution of the specific surface area of surface snow layers, Environ. Sci.
Technol., 37, 661-666, 2003.

Caya, D. and Laprise, R.: A semi-implicit semi-Lagrangian regional climate model: the Canadian RCM, Mon. Weather Rev., 127, 341-362, 1999.

Chen, S. and Baker, I.: Evolution of individual snowflakes during metamorphism, J. Geophys. Res., 115, D21114, doi:10.1029/2010JD014132, 2010.

Colbeck, S.: Theory of metamorphism of dry snow, J. Geophys. Res., 88, 5475-5482, 1983.

Derksen, C., Toose, P., Lemmetyinen, J., Pulliainen, J., Langlois, A., Rutter, N., and Fuller, M.: Evaluation of passive microwave brightness temperature simulations and snow water equivalent retrievals through a winter season, Remote Sens. Environ., 117, 236-248, 2012.

Domine, F., Cabanes, A., Taillandier, A., and Legagneux, L.: Specific surface area of snow samples determined by $\mathrm{CH}_{4}$ adsorption at $77 \mathrm{~K}$ and estimated by optical microscopy and scanning electron microscopy, Environ. Sci. Technol., 35, 771-780, 2001.

Domine, F., Lauzier, T., Cabanes, A., Legagneux, L., Kuhs, W., Techmer, K., and Heinrichs, T.: Snow metamorphism as revealed by scanning electron microscopy, Microsc. Res. Techniq., 62, 33-48, 2003.

Domine, F., Taillandier, A.-S., and Simpson, W. R.: A parameterization of the specific surface area of seasonal snow for field use and for models of snowpack evolution, J. Geophys. Res., 112, F02031, doi:10.1029/2006JF000512, 2007.

Domine, F., Albert, M., Huthwelker, T., Jacobi, H.-W., Kokhanovsky, A. A., Lehning, M., Picard, G., and Simpson, W. R.: Snow physics as relevant to snow photochemistry, Atmos. Chem. Phys., 8, 171-208, doi:10.5194/acp-8-171-2008, 2008.

Domine, F., Taillandier, A.-S., Cabanes, A., Douglas, T. A., and Sturm, M.: Three examples where the specific surface area of snow increased over time, The Cryosphere, 3, 31-39, doi:10.5194/tc-3-31-2009, 2009.

Durand, M. and Liu, D.: The need for prior information in characterizing snow water equivalent from microwave brightness temperatures, Remote Sens. Environ., 126, 248-257, 2012.

Durand, M., Kim, E. C., and Margulis, S.: Quantifying uncertainty in modeling snow microwave radiance for a mountain snowpack at the point-scale, including stratigraphic effects, IEEE T. Geosci. Remote, 46, 1753-1767, 2008.

Durand, M., Kim, E., and Margulis, S.: Radiance assimilation shows promise for snowpack characterization, Geophys. Res. Lett., 36, L02503, doi:10.1029/2008GL035214, 2009.

Ettema, J., van den Broeke, M. R., van Meijgaard, E., van de Berg, W., Bamber, J. L., Box, J. E., and Bales, R. C.: Higher surface mass balance of the Greenland ice sheet revealed by highresolution climate modeling, Geophys. Res. Lett., 36, L12501, doi:10.1029/2009GL038110, 2009.

Flanner, M. and Zender, C.: Linking snowpack microphysics and albedo evolution, J. Geophys. Res., 111, D12208, doi:10.1029/2005JD006834, 2006.

Flanner, M., Zender, C., Randerson, J., and Rasch, P.: Present-day climate forcing and response from black carbon in snow, J. Geophys. Res., 112, D11202, doi:10.1029/2006JD008003, 2007.

Flin, F. and Brzoska, J.: The temperature-gradient metamorphism of snow: vapour diffusion model and application to tomographic images, Ann. Glaciol., 49, 17-21, 2008. 
Flin, F., Brzoska, J., Lesaffre, B., Coléou, C., and Pieritz, R.: Threedimensional geometric measurements of snow microstructural evolution under isothermal conditions, Ann. Glaciol., 38, 39-44, 2004.

Franz, K., Butcher, P., and Ajami, N.: Addressing snow model uncertainty for hydrologic prediction, Adv. Water Resour., 33, 820 $832,2010$.

Gallet, J.-C., Domine, F., Zender, C. S., and Picard, G.: Measurement of the specific surface area of snow using infrared reflectance in an integrating sphere at 1310 and $1550 \mathrm{~nm}$, The Cryosphere, 3, 167-182, doi:10.5194/tc-3-167-2009, 2009.

Gardner, A. and Sharp, M.: A review of snow and ice albedo and the development of a new physically based broadband albedo parameterization, J. Geophys. Res., 115, F01009, doi:10.1029/2009JF001444, 2010.

Gouttevin, I., Menegoz, M., Domine, F., Krinner, G., Koven, C., Ciais, P., Tarnocai, C., and Boike, J.: How the insulating properties of snow affect soil carbon distribution in the continental pan-arctic area, J. Geophys. Res., 117, G02020, doi:10.1029/2011JG001916, 2012.

Grody, N.: Relationship between snow parameters and microwave satellite measurements: theory compared with Advanced Microwave Sounding Unit observations from 23 to $150 \mathrm{GHz}$, J. Geophys. Res., 113, D22108, doi:10.1029/2007JD009685, 2008.

Hedstrom, N. and Pomeroy, J.: Measurements and modelling of snow interception in the boreal forest, Hydrol. Process., 12, 1611-1625, 1998.

Huang, C., Margulis, S., Durand, M., and Musselman, K.: Assessment of Snow Grain-Size Model and Stratigraphy Representation Impacts on Snow Radiance Assimilation: Forward Modeling Evaluation, IEEE T. Geosci. Remote, 50, 4551-4564, 2012.

Jacobi, H.-W., Domine, F., Simpson, W. R., Douglas, T. A., and Sturm, M.: Simulation of the specific surface area of snow using a one-dimensional physical snowpack model: implementation and evaluation for subarctic snow in Alaska, The Cryosphere, 4, 35-51, doi:10.5194/tc-4-35-2010, 2010.

Jin, Z., Charlock, T. P., Yang, P., Xie, Y., and Miller, W.: Snow optical properties for different particle shapes with application to snow grain size retrieval and MODIS/CERES radiance comparison over Antarctica, Remote Sens. Environ., 112, 3563-3581, 2008.

Kaempfer, T. and Schneebeli, M.: Observation of isothermal metamorphism of new snow and interpretation as a sintering process, J. Geophys. Res., 112, D24101, doi:10.1029/2007JD009047, 2007.

Kokhanovsky, A. A. and Zege, E. P.: Scattering optics of snow, Appl. Optics, 43, 1589-1602, 2004.

Kondo, J. and Yamazaki, T.: A prediction model for snowmelt, snow surface temperature and freezing depth using a heat balance method, J. Appl. Meteorol., 29, 375-384, 1990.

Kontu, A. and Pulliainen, J.: Simulation of spaceborne microwave radiometer measurements of snow cover using in situ data and brightness temperature modeling, IEEE T. Geosci. Remote, 48, 1031-1044, 2010.

Langlois, A., Brucker, L., Kohn, J., Royer, A., Derksen, C., Cliche, P., Picard, G., Willemet, J. M., and Fily, M.: Simulation of snow water equivalent (SWE) using thermodynamic snow models in Québec, Canada, J. Hydrometeorol., 10, 1447-1463, 2009.
Langlois, A., Royer, A., Derksen, C., Montpetit, B., Dupont, F., and Goïta, K.: Coupling the snow thermodynamic model SNOWPACK with the microwave emission model of layered snowpacks for subarctic and arctic snow water equivalent retrievals, Water Ressour. Res., 48, W12524, doi:10.1029/2012WR012133, 2012.

Langlois, A., Bergeron, J., Brown, R., Royer, A., Harvey, R., Roy, A., Wang, L., and Thériault, N.: Evaluation of CLASS 2.7 and 3.5 simulations of snow cover from the Canadian Climate model (CRCM4) over Québec, Canada, J. Hydrometeorol., submitted (AMSJHM-S-13-00073), 2013.

Leathers, D. J., Palecki, M. A., Robinson, D. A., and Dewey, K. F.: Climatology of the daily temperature range annual cycle in the United States, Clim. Res., 9, 197-211, 1998.

Legagneux, L., Lauzier, T., Domine, F., Kuhs, W., Heinrichs, T., and Techmer, K.: Rate of decay of specific surface area of snow during isothermal experiments and morphological changes studied by scanning electron microscopy, Can. J. Phys., 81, 459-468, 2003.

Li, L. and Pomeroy, J.: Estimates of threshold wind speeds for snow transport using meteorological data, J. Appl. Meteorol., 36, 205213, 1997.

Liston, G. and Hiemstra, C.: The changing cryosphere: Pan-Arctic snow trends (1979-2009), J. Climate, 24, 5691-5712, 2011.

Lyapustin, A., Tedesco, M., Wang, Y., Aoki, T., Horif, M., and Kokhanovsky, A. A.: Retrieval of snow grain size over Greenland from MODIS, Remote Sens. Environ., 113, 1976-1987, 2009.

Marbouty, D.: An experimental study of temperature gradient metamorphism, J. Glaciol., 26, 303-312, 1980.

Mesinger, F., DiMego, G., Kalnay, E., Mitchell, K., Shafran, P., Ebisuzaki, W., Jovic, D., Woollen, J., Rogers, E., and Berbery, E.: North American regional reanalysis, B. Am. Meteorol. Soc., 87, 343-360, 2006.

Montpetit, B., Royer, A., Langlois, A., Cliche, P., Roy, A., Champollion, N., Picard, G., Domine, F., and Obbard, R.: New shortwave infrared albedo measurements for snow specific surface area retrieval, J. Glaciol., 58, 941, doi:10.1016/j.coldregions.2010.01.004, 2012.

Montpetit, B., Royer, A., Roy, A., Langlois, L., and Derksen, D.: Snow microwave emission modeling of ice lenses within a snowpack using the microwave emission model for layered snowpacks, IEEE T. Geosci. Remote, available online, doi:10.1109/TGRS.2013.2250509, 2013.

Morin, S., Lejeune, Y., Lesaffre, B., Panel, J.-M., Poncet, D., David, P., and Sudul, M.: An 18-yr long (1993-2011) snow and meteorological dataset from a mid-altitude mountain site (Col de Porte, France, $1325 \mathrm{~m}$ alt.) for driving and evaluating snowpack models, Earth Syst. Sci. Data, 4, 13-21, doi:10.5194/essd-4-13-2012, 2012.

Morin, S., Domine, F., Dufour, A., Lejeune, Y., Lesaffre, B., Willemet, J., Carmagnola, C., and Jacobi, H.: Measurements and modeling of the vertical profile of specific surface area of an alpine snowpack, Adv. Water Resour., 55, 111-120, doi:10.1016/j.advwatres.2012.01.010, 2013.

Music, B. and Caya, D.: Evaluation of the hydrological cycle over the Mississippi River basin as simulated by the Canadian Regional Climate Model (CRCM), J. Hydrometeorol., 8, 969-988, 2007.

Niwano, M., Aoki, T., Kuchiki, K., Hosaka, M., and Kodama, Y.: Snow metamorphism and albedo process (SMAP) model for cli- 
mate studies: Model validation using meteorological and snow impurity data measured at Sapporo, Japan, J. Geophys. Res., 117, F03008, doi:10.1029/2011JF002239, 2012.

Pardé, M., Goïta, K., and Royer, A.: Inversion of a passive microwave snow emission model for water equivalent estimation using airborne and satellite data, Remote Sens. Environ., 111, 346-356, 2007

Picard, G., Brucker, L., Roy, A., Dupont, F., Fily, M., and Royer, A.: Simulation of the microwave emission of multi-layered snowpacks using the dense media radiative transfer theory: the DMRT-ML model, Geosci. Model Dev. Discuss., 5, 3647-3694, doi:10.5194/gmdd-5-3647-2012, 2012.

Pietroniro, A., Leconte, R., Toth, B., Peters, D. L., Kouwen, N., Conley, F. M., and Prowse, T.: Modelling climate change impacts in the Peace and Athabasca catchment and delta III - integrated model assessment, Hydrol. Process., 20, 4231-4235, 2006.

Pinzer, B. and Schneebeli, M.: Snow metamorphism under alternating temperature gradients: morphology and recrystallization in surface snow, Geophys. Res. Lett., 36, L23503, doi:10.1029/2009GL039618, 2009.

Reichle, R.: Data assimilation methods in the Earth sciences, Adv. Water Resour., 31, 1411-1418, 2008.

Roy, V., Goïta, K., Royer, A., Walker, A., and Goodison, B.: Snow water equivalent retrieval in a Canadian boreal environment from microwave measurements using the HUT snow emission model, IEEE T. Geosci. Remote, 42, 1850-1859, 2004.

Roy, A., Picard, G., Royer, A., Montpetit, B., Dupont, F., Langlois, A., Derksen, C., and Champollion, N.: Brightness temperature simulations of the Canadian seasonal snowpack driven by measurements of the snow specific surface area, IEEE T. Geosci. Remote, available online, doi:10.1109/TGRS.2012.2235842, 2013.

Rutter, N., Essery, R., Pomeroy, J., Altimir, N., Andreadis, K., Baker, I., Barr, A., Bartlett, P., Boone, A., Deng, H., Douville, H., Dutra, E., Elder, K., Ellis, C., Feng, X., Gelfan, A., Goodbody, A., Gusev, Y., Gustafsson, D., Hellström, R., Hirabayashi, Y., Hirota, T., Jonas, T., Koren, V., Kuragina, A., Lettenmaier, D., Li, W., Luce, C., Martin, E., Nasonova, O., Pumpanen, J., Pyles, R. D., Samuelsson, P., Sandells, M.,Schädler, G., Shmakin, A., Smirnova, T. G., Stähli, M., Stöckli, R., Strasser, U., Su, H., Suzuki, K., Takata, K., Tanaka, K., Thompson, E., Vesala, T., Viterbo, P., Wiltshire, A., Xia, K., Xue, Y., and Yamazaki, T.: Evaluation of forest snow processes models (SnowMIP2), J. Geophys. Res., 114, D06111, doi:10.1029/2008JD011063, 2009.

Scinocca, J. F., McFarlane, N. A., Lazare, M., Li, J., and Plummer, D.: Technical Note: The CCCma third generation AGCM and its extension into the middle atmosphere, Atmos. Chem. Phys., 8, 7055-7074, doi:10.5194/acp-8-7055-2008, 2008.
Sommerfeld, R. and LaChapelle, E.: The classification of snow metamorphism, J. Glaciol., 9, 3-17, 1970.

Sturm, M., Holmgren, J., König, M., and Morris, K.: The thermal conductivity of seasonal snow, J. Glaciol., 43, 26-41, 1997.

Sun, S., Jin, J., and Xue, Y.: A simple snow-atmosphere-soil transfer model, J. Geophys. Res., 104, 19587-19597, 1999.

Taillandier, A.-S., Domine, F., Simpson, W. R., Sturm, M., Douglas, T. A., and Severin, K.: Evolution of the snow area index of the subarctic snowpack in central Alaska over a whole season, consequences for the air to snow transfer of pollutants, Environ. Sci. Technol., 40, 7521-7527, 2006.

Taillandier, A.-S., Domine, F., Simpson, W. R., Sturm, M., and Douglas, T. A.: Rate of decrease of the specific surface area of dry snow: Isothermal and temperature gradient conditions, J. Geophys. Res., 112, F03003, doi:10.1029/2006JF000514, 2007.

Teutschbein, C. and Seibert, J.: Regional climate models for hydrological impact studies at the catchment scale: a review of recent modeling strategies, Geography Compass, 4, 834-860, 2010.

Toure, A., Goïta, K., Royer, A., Kim, E., Durand, M., Margulis, S., and Lu, H.: A Case study of using a multilayered thermodynamical snow model for radiance assimilation, IEEE T. Geosci. Remote, 9, 2828-2837, 2011.

Turcotte, R., Fortin, L.-G., Fortin, V., Fortin, J.-P., and Villeneuve, J.-P.: Operational analysis of the spatial distribution and the temporal evolution of the snowpack water equivalent in southern Québec, Canada, Nord. Hydrol., 38, 211-234, 2007.

Vachon, F., Goïta, K., De Sève, D., and Royer, A.: Inversion of a snow emision model calibrated with in situ data for snow water equivalent monitoring, IEEE T. Geosci. Remote, 48, 59-71, 2010.

Verseghy, D.: CLASS-A Canadian land surface scheme for GCMs, I. Soil model, Int. J. Climateol., 11, 111-133, 1991.

Verseghy, D.: CLASS - The Canadian Land Surface Scheme (Version 3.4): Technical Documentation (Version 1.1), 2009.

Verseghy, D., McFarlane, N., and Lazare, M.: CLASS-A Canadian land surface scheme for GCMs, II. Vegetation model and coupled runs, Int. J. Climateol., 13, 347-370, 1993.

Vionnet, V., Brun, E., Morin, S., Boone, A., Faroux, S., Le Moigne, P., Martin, E., and Willemet, J.-M.: The detailed snowpack scheme Crocus and its implementation in SURFEX v7.2, Geosci. Model Dev., 5, 773-791, doi:10.5194/gmd-5-7732012, 2012.

Wiscombe, W. and Warren, S.: A model for the spectral albedo of snow, I: Pure snow, J. Atmos. Sci., 37, 2712-2733, 1980. 